\title{
Analysis of Pro- and Antioxidant Status in Women with Endocrine Infertility
}

\author{
Lyudmila A. Grebenkina, PhD, ScD; Marina A. Darenskaya, PhD, ScD; \\ Maria A. Rashidova, PhD*; Elena V. Osipova, $\mathrm{PhD}, \mathrm{ScD}$; Anastasia S. Lyubochko; \\ Sergey I. Kolesnikov, $\mathrm{PhD}, \mathrm{ScD}$, Member of the RAS; Lyubov I. Kolesnikova, PhD, ScD, \\ Member of the RAS
}

\author{
Scientific Centre for Family Health and Human Reproduction Problems \\ Irkutsk, the Russian Federation
}

\begin{abstract}
The aim of our study was to identify the changes in the indicators of lipid peroxidation (LPO) and antioxidant defense (AOD) in women with endocrine infertility.

Methods and Results: The study included 358 women of reproductive age. Based on clinical and laboratory data, two groups were formed: the control group (CG) and the main group (MG). CG consisted of 61 healthy fertile women (mean age of $22 \pm 2.3$ years). MG consisted of 297 women (mean age of $26 \pm 5.6$ years) with endocrine infertility. The blood levels of antioxidant parameters (total antioxidant activity [TTA], SOD activity, $\alpha$-tocopherol and retinol) and primary/secondary products of LPO (conjugated dienes [CD], ketodienes and conjugated trienes [KD-CT], and thiobarbituric acid reactants [TBARs]) were determined using spectrophotometric and fluorometric methods. The levels of sex hormones and cortisol were determined by radioimmunoassay and EIA.

In MG, we found a significant increase in the blood levels of total lipid, DB, CDs, KD-CT, and TBARs, compared to CG. The results of a comparative analysis of the AOD parameters showed a significant increase in the total AOA level by $31 \%$ in $\mathrm{MG}$, while the levels of $\alpha$-tocopherol and retinol significantly decreased by $22 \%$ and $15 \%$, respectively, compared to CG. In women of $\mathrm{MG}$, the serum level of prolactin increased by 2 times.

Conclusion: The results obtained reflect the adaptive and disadaptive mechanisms of LPO-AOD participation in the formation of female infertility of endocrine origin. The complex changes in the LPO-AOD system (increased levels of the substrates of oxidation and all intermediates of the LPO process amid falling values of the AOD parameters) indicate the presence of OS in women with endocrine infertility. (International Journal of Biomedicine. 2020;10(4):373-377.)
\end{abstract}

Key Words: women $\bullet$ lipid peroxidation $\bullet$ antioxidant defense $\bullet$ endocrine infertility

\section{Abbreviations}

AOD, antioxidant defense; CDs, conjugated dienes; DB, double bonds; FSH, follicle-stimulating hormone; GSH, reduced glutathione; GSSG, oxidized glutathione; KD-CT, ketodienes and conjugated trienes; LH, luteinizing hormone; LPO, lipid peroxidation; OS, oxidative stress; PRL, prolactin; ROS, reactive oxygen species; SOD, superoxide dismutase; TAA, total antioxidant activity; TBARs, thiobarbituric acid reactants; WHO, world health organization; 17-OH-Pg, 17-OH-progesterone; GSH, reduced glutathione; GSSG, oxidized glutathione.

\section{Introduction}

The non-specific biochemical processes that occur at the cellular level and determine the reactivity of the body are essential in the pathogenesis of neuroendocrine diseases of the reproductive system. ${ }^{(1-7)}$ It is known that the reactions of lipid peroxidation (LPO) and antioxidant defense (AOD) provide cellular homeostasis at the optimal level. In disregulatory states, as a result of the LPO activation, a violation of the pro-oxidant-antioxidant balance occurs, which indicates the development of oxidative stress (OS). ${ }^{(8,9)}$

One of the most powerful factors that damage cell membranes is the formation of free radicals, which cause chain reactions of lipid oxidation in the cell. Especially 
susceptible to free radical oxidation are membrane phospholipids unsaturated fatty acids. Excessive activity of free radical lipid oxidation processes is prevented by a special AOD system. AOD plays an important role in the body's protective and adaptive responses. The study of the balance of indicators of the free radical lipid oxidation processes and AOD in various pathological processes allows us to assess patients' reserve capabilities. ${ }^{(10,11)}$

To fully understand the nature of peroxidation processes in reproductive disorders, and when to choose tactics for rational correction of their possible damaging effects, a comprehensive examination is necessary, including assessment of both the initial and final LPO products, as well as the level of factors that provide defense from possible damage to the cell regulatory apparatus by intermediates of LPO. ${ }^{(12)}$ Women's reproductive health protection is one of the crucial tasks of healthcare. Despite the advances in modern medicine and the development and implementation of new reproductive technologies, the number of infertile couples continues to increase and, according to the literature, the frequency of infertility in various countries of the world varies from $8 \%$ to $21 \%$, and the endocrine female infertility accounts for about $30 \%-40 \%{ }^{(13,14)}$

Despite extensive study of the main mechanisms of pathogenesis, and of factors that prevent the development of the most common clinical and pathogenetic variants of female endocrine infertility and reproductive disorders, the background of hormone-dependent gynecological diseases is still not clear. It concerns functional relationships between the processes of LPO and neuroendocrine regulation of reproductive disorders, which is important for women with endocrine infertility. ${ }^{(15,16)}$

The aim of our study was to identify the changes in the indicators of LPO and AOD in women with endocrine infertility.

\section{Materials and Methods}

The study was conducted in accordance with ethical principles of the WMA Declaration of Helsinki (1964, ed. 2013) and approved by the Ethics Committee of Scientific Centre for Family Health and Human Reproduction Problems. Written informed consent was obtained from the patient/ parent/guardian/ relative of each patient.

To evaluate the parameters of the LPO-AOD system, 358 women of reproductive age were selected. When assigning women to a particular category (fertile or infertile), the WHO classification of fertility was used: fertile (women who had a pregnancy during the current year), presumably fertile (women who had a history of pregnancy more than 1 year ago), primarily infertile (women who did not have a history of pregnancy, despite regular sexual contact during the year and provided that no contraceptive methods were used), secondarily infertile (infertile women with a history of pregnancy), women with unknown fertility (women with no history of pregnancy due to the use of contraceptive methods, and/or with irregular sexual contact). Women with unknown fertility were not included in the study.
Based on clinical and laboratory data, taking into account the accepted criteria, two groups were formed: the control group (CG) and the main group (MG). CG consisted of 61 healthy fertile women (mean age of $22 \pm 2.3$ years).

The criteria for inclusion in the CG: pregnancy that ended in childbirth within the last 2 years, absence of neuroendocrine disorders, regular menstrual cycle, and absence of severe somatic pathology. MG consisted of 297 infertile women (mean age of $26 \pm 5.6$ years) with the following nosological forms and syndromes: hypothalamic syndrome $(\mathrm{n}=108)$, hyperprolactinemia $(\mathrm{n}=60)$, congenital adrenal cortex dysfunction $(n=32)$, and dyshormonal diseases of the mammary glands $(\mathrm{n}=97)$. Women of all infertile subgroups were comparable in age, reproductive history, and duration of infertility.

Blood samples $(5 \mathrm{ml})$ were collected from the ulnar vein in standard vacuum tubes with EDTA in the morning after night fasting. The erythrocyte population was separated from the other blood components by centrifugation at $1500 \mathrm{~g}$ for 5 $\min$, at $4{ }^{\circ} \mathrm{C}$. The erythrocyte pellet was washed 3 times with a $0.9 \%$ (wt $/ \mathrm{vol}$ ) $\mathrm{NaCl}$ solution. Aliquots of EDTA anticoagulated plasma and washed erythrocytes were used immediately or kept frozen at $-40^{\circ} \mathrm{C}$, not exceeding one month. Total lipids were measured by colorimetric kit assay (BIOLA-TEST, PLIVA - Lachema a.s., Czech Republic).

The intensity of LPO-AOD processes was estimated by plasma concentrations of antioxidant parameters (TAA, SOD activity, $\alpha$-tocopherol and retinol) and primary/secondary products of LPO (CDs, KD-CT, and TBARS). ${ }^{(17,18)}$ The blood plasma TAA level was detected photometrically. ${ }^{(19)}$ TBARs levels, SOD activity in hemolysate and $\alpha$-tocopherol and retinol levels in plasma were detected by fluorometry. (20) The content of GSH and GSSG was determined by P.Y. Hissin, R. Hilf (1976). ${ }^{(21)}$ The SOD activity in the erythrocytes was determined by H.P. Misra and I. Fridovich. (22) The measurements were conducted with a Shimadzu RF-1501 spectrophotometer (Japan) consisting of two blocks: a UV-1650PC spectrophotometer and a RF-1501 spectrofluorimeter.

The levels of LH, FSH, PRL in the blood were detected by radioimmunoassay with an Immunotest Analyzer (Russia) using commercial kits from Dias (Russia). The level of cortisol was determined by EIA with EL 808 analyzer (USA) using test system "ALKOR-BIO" (Russia), 17-OHprogesterone a COBOS analyzer (USA) using kits from DRG ELISAS (USA).

Statistical analysis was performed using the Statistica 6.1 software package (Stat-Soft Inc., USA). The normality of distribution of continuous variables was tested by the Kolmogorov-Smirnov test with the Lilliefors correction and Shapiro-Wilk test. For descriptive analysis, results are presented as mean \pm standard deviation (SD). For data with normal distribution, inter-group comparisons were performed using Student's t-test. Differences of continuous variables departing from the normal distribution, even after transformation, were tested by the Mann-Whitney U-test. A probability value of $P<0.05$ was considered statistically significant. 


\section{Results}

In $\mathrm{MG}$, total lipid concentrations increased by $8 \%$ and DB - by $13 \%$, compared to CG. Activation of the LPO process, leading to the accumulation of the toxic products, was characterized by an increase in the levels of the lipid oxidation primary and secondary products $[\mathrm{CDs}-$ by $20 \%(\mathrm{p}<0.05)$, KD-CT - by $29 \%(\mathrm{p}<0.05)]$, as well as a significant increase in the level of TBARs (Fig.1).

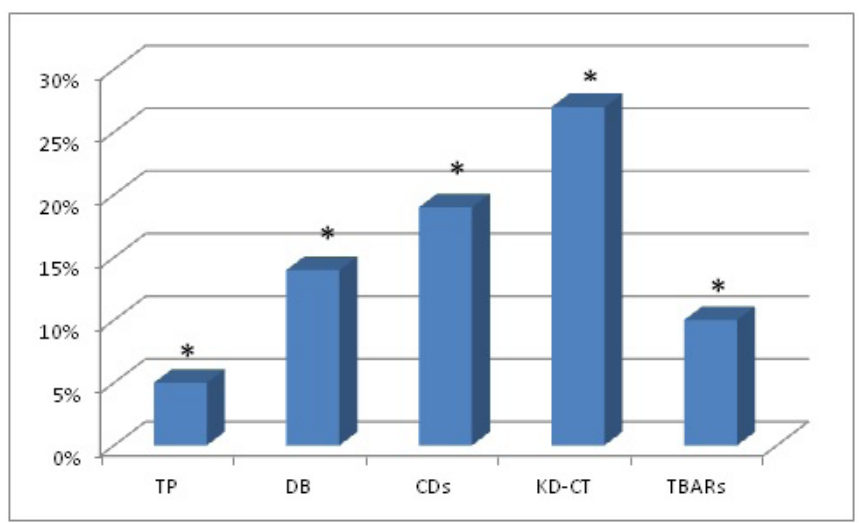

Fig. 1. The blood levels of oxidation substrates and LPO products in study groups. $(0-$ the level of the control group indicators, taken as $100 \%$; * $P<0.05$ ).

The results of a comparative analysis of the AOD parameters showed a significant increase in the total AOA level by $31 \%$ in MG, while the levels of $\alpha$-tocopherol and retinol significantly decreased by $22 \%$ and $15 \%$, respectively, compared to CG. The SOD activity was $6 \%$ lower than in CGThe blood level of GSSG increased by $5 \%$ and the GSH/GSSG ratio decreased insignificantly by $5 \%$ in MG, compared to CG (Fig.2).

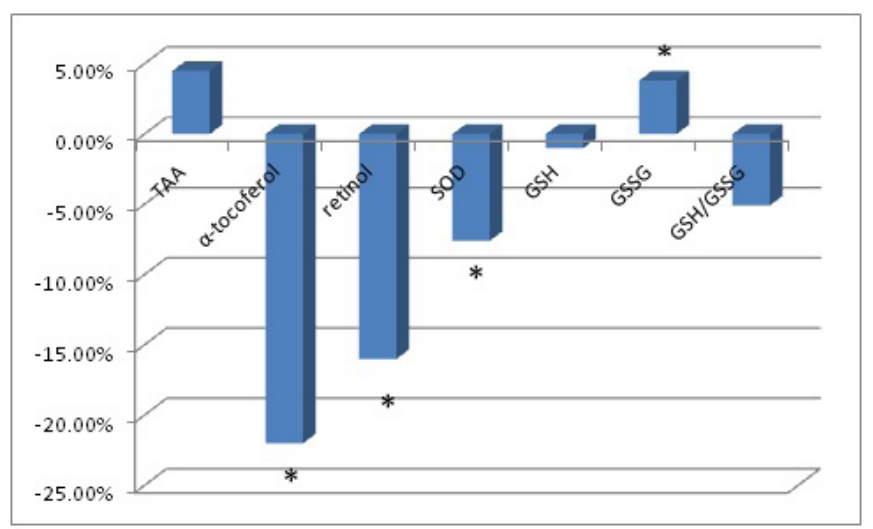

Fig. 2. The blood levels of $A O D$ indicators in study groups. $(0-$ the level of the control group indicators, taken as $100 \%$; $-P<0.05)$.

In women of MG, the serum level of PRL increased by 2 times, and the LH/FSH ratio was $19 \%$ higher than in CG; there were no significant differences in the levels of LH and FSH between groups (Fig.3). We found also a 17\% increase in the levels of cortisol and a $19 \%$ increase in $17-\mathrm{OH}-$ progesterone in $\mathrm{MG}$, compared to CG. No significant differences in the serum levels of testosterone, thyroid and thyroid-stimulating hormones were revealed between study groups.

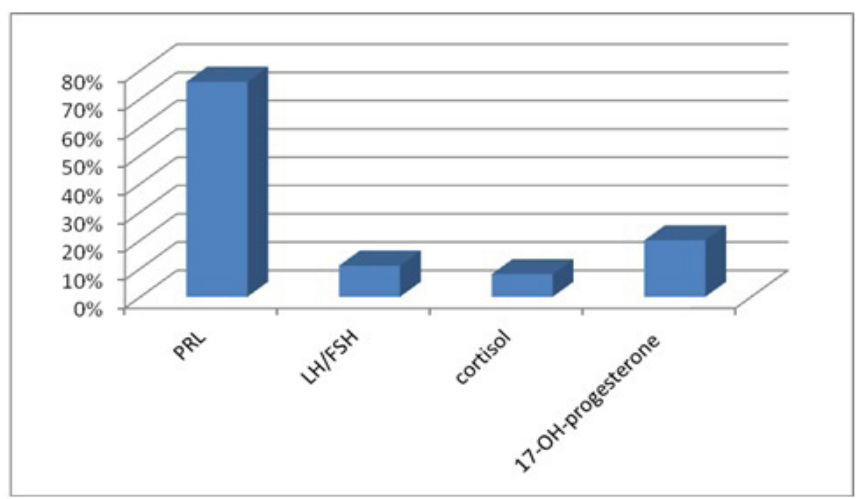

Fig. 3. The blood levels of sex hormones and cortisol in study groups. $(0-$ the level of the control group indicators, taken as $100 \%$; $*-P<0.05$ )

Biochemical studies of human reproductive function and its disorders in recent decades have been characterized by the development of "cost-effective" universal technologies that allow us to give an integral assessment and outline some sanogenetic ways to correct disorders in reproductive function. It is necessary to highlight the research concerning the polyvalent function of LPO and AOD factors, ${ }^{(23)}$ which prevent the development of OS and positively affect the complex treatment of endocrine forms of female infertility. ${ }^{(24,25)}$

The increased intensity of LPO, as a possible result of neurohumoral shifts, in many cases is either a consequence or cause of certain pathological changes in cells and tissues. ${ }^{(26,27)}$

The concentration of highly reactive LPO products is controlled by a multicomponent system of AOD, formed during evolution, that prevents the formation of OS. ${ }^{(28)}$

In a healthy subject, the actions of antioxidants are closely related to each other and are clearly balanced. Violation of the ratio of enzymatic and non-enzymatic components of AOD can cause additional activation in LPO processes and depletion of antioxidant reserves, leading to the development of OS. In our study, the analysis of the antioxidant system factors demonstrated either reduced concentration ( $\alpha$-tocopherol, retinol) and low activity (superoxide dismutase), or almost unchanged levels (glutathione system).

The decrease of retinol concentration in women with endocrine infertility, compared to women of $\mathrm{CG}$, deserves special attention. This fact should be attributed not so much to the lower antioxidant status of the blood plasma of these patients, but to the fact that during its oxidation vitamin $\mathrm{A}$ is converted to retinoic acid. ${ }^{(29)}$ Retinoic acid is currently considered as a lipophilic hormone that interacts with the nucleus of target cells like steroid hormones. The resulting complex binds to certain parts of the DNA and stimulates gene transcription. Proteins formed as a result of gene stimulation under the influence of retinoic acid affect the growth, differentiation, and regeneration of tissues. In this regard, retinol can be considered not only a 
direct-acting antioxidant, responsible together with tocopherols for the "quenching" of peroxide radicals, but also a factor that has an antioxidant-mediated effect through the hormonal regulation of systemic metabolism and the functioning of many organs and systems. ${ }^{(30)}$ This possibility is indicated by the results of studies that have shown retinoic acid binds to the receptors of vessels of smooth muscles, whose nuclei are constantly in the "stand by" mode, activating the corresponding regions of DNA with the formation of adrenomedullin, which induces a variety of systemic effects. ${ }^{(31)}$

Of considerable interest is also the fact that in the group of patients with endocrine infertility, prolactin content is twice as high as in healthy women. According to the literature data on the effect of prolactin on lipid metabolism, women have a positive correlation between the content of triacylglycerols and prolactin. ${ }^{(32)}$ The results suggest the possibility of increasing the activity of liposynthetic processes in the liver, a possibility that is also evidenced by data on an increase in the concentration of free fatty acids, cholesterol, and triacylglycerols in animals after intraperitoneal administration of prolactin. ${ }^{(33)}$ Prolactin inhibits human lipoprotein lipase activity in white adipose tissue, ${ }^{(34)}$ thereby maintaining a high concentration of lipids in the blood. In this regard, a paradoxical metabolic situation arises: in the presence of absorptive lipemia, triacylglycerols are not attacked by the prolactin-blocked lipoprotein lipase and do not replenish the fat depot. The formation of fatty acids de novo, and lipids from them, is prevented by the depression of malonyl-CoA synthetase, which can occur at the level of apoenzyme, coenzymes, or cofactors. At the same time, the residues of unsaturated fatty acids remaining in the blood for a long time in the composition of LDL are very likely to undergo lipid peroxidation, which we observe when the concentration of prolactin increases.

Thus, our results reflect the adaptive and disadaptive mechanisms of LPO-AOD participation in the formation of female infertility of endocrine origin. Taking into account the complex changes in the LPO-AOD system, indicating the presence of OS (increased levels of the substrates of oxidation and all intermediates of the LPO process amid falling values of the AOD parameters), we recommend the differentiated complex treatment and preventive measures aimed at normalizing the of LPO-AOD balance in women with endocrine infertility.

\section{Competing Interests} interests.

\section{References}

1. Lu J, Wang Z, Cao J, Chen Y, Dong Y. A novel and compact review on the role of oxidative stress in female reproduction. Reprod Biol Endocrinol. 2018 Aug 20;16(1):80. doi: 10.1186/ s12958-018-0391-5.

2. Wojsiat J, Korczyński J, Borowiecka M, Żbikowska HM. The role of oxidative stress in female infertility and in vitro fertilization. Postepy Hig Med Dosw (Online). 2017 May
9;71(0):359-366. doi: 10.5604/01.3001.0010.3820.

3. Wagner H, Cheng JW, Ko EY. Role of reactive oxygen species in male infertility: An updated review of literature. Arab J Urol. 2017 Dec 8;16(1):35-43. doi: 10.1016/j. aju.2017.11.001.

4. Kolesnikova LI, Grebenkina LA, Darenskaya MA, Vlasov BYa. [Oxidative stress as a nonspecific pathogenetic link in reproductive disorders (review)]. Siberian Scientific Medical Journal. 2012;2(1): 58-66. [Article in Russian].

5. Kolesnikova LI, Kolesnikov SI, Darenskaya MA, Grebenkina LA, Nikitina OA, Lazareva LM, Suturina LV, Danusevich IN, Druzhinina EB, Semendyaev AA. Activity of LPO Processes in Women with Polycystic Ovarian Syndrome and Infertility. Bull Exp Biol Med. 2017 Jan;162(3):320-322. doi: 10.1007/s10517-017-3605-5.

6. Agarwal A, Gupta S, Sharma RK. Role of oxidative stress in female reproduction. Reprod Biol Endocrinol. 2005 Jul 14;3:28. doi: 10.1186/1477-7827-3-28.

7. Agarwal A, Gupta S, Sekhon L, Shah R. Redox considerations in female reproductive function and assisted reproduction: from molecular mechanisms to health implications. Antioxid Redox Signal. 2008 Aug;10(8):1375403. doi: 10.1089/ars.2007.1964.

8. Agarwal A, Aponte-Mellado A, Premkumar BJ, Shaman A, Gupta S. The effects of oxidative stress on female reproduction: a review. Reprod Biol Endocrinol. 2012 Jun 29;10:49. doi: 10.1186/1477-7827-10-49.

9. Sies H. Oxidative stress: a concept in redox biology and medicine. Redox Biology. 2015;4:180-183.

10. Bjørklund G, Chirumbolo S. Role of oxidative stress and antioxidants in daily nutrition and human health. Nutrition. 2017 Jan;33:311-321. doi: 10.1016/j.nut.2016.07.018.

11. Niki E. Oxidative stress and antioxidants: Distress or eustress? Arch Biochem Biophys. 2016 Apr 1;595:19-24. doi: 10.1016/j.abb.2015.11.017.

12. Kolesnikova L, Semenova N, Madaeva I, Suturina L, Solodova E, Grebenkina L, Darenskaya M. Antioxidant status in peri- and postmenopausal women. Maturitas. 2015 May;81(1):83-7. doi: 10.1016/j.maturitas.2015.02.264.

13. Wolff M., Stute P. Gynecological endocrinology and reproductive medicine. Authorized translation of the first German language edition M. von Wolff, P. Stute "Gynäkologische Endokrinologie und Reproduktionsmedizin" by Hkalatov V.Yu. and edited by Andreeva EN. M.: MEDpressinform; 2017.[In Russian].

14. Podzolkova NM, Shamugia NL, Koloda YuA, Skvortsova MYu. Infertility. Diagnostics, modern methods of treatment. M.: GEOTAR-Media; 2018. [In Russian].

15. Kolesnikova LI, Osipova EV, Grebenkina LA. Oxidative stress in reproductive endocrine disorders in women. Novosibirsk: Nauka; 2011. [In Russian].

16. Kolesnikova LI, Darenskaya MA, Kolesnikov SI. [Free radical oxidation: a pathophysiologist's view]. Bulletin of Siberian Medicine. 2017;16(4):16-29. [Article in Russian]. Doi:10.20538/1682-0363-2017-4-16-29.

17. Volchegorskiı̌ IA, Nalimov AG, Iarovinskiǔ BG, Lifshits RI. [Comparison of various approaches to the determination of the products of lipid peroxidation in heptane-isopropanol extracts of blood]. Vopr Med Khim. 1989;35(1):127-31. [Article in Russian].

18. Gavrilov VB, Gavrilova AR, Mazhul' LM. [Methods of determining lipid peroxidation products in the serum using a thiobarbituric acid test].Vopr Med Khim. 1987;33(1):118-22. 
[Article in Russian].

19. Klebanov GI, Babenkova IV, Teselkin IuO, Komarov OS, Vladimirov IuA. [Evaluation of the antioxidative activity of blood plasma using yolk lipoproteins]. Lab Delo. 1988;(5):5962.[Article in Russian].

20. Cherniauskene RCh, Varshkiavichene ZZ, Gribauskas PS. [Simultaneous fluorometric determination of the concentrations of vitamins E and A in blood serum]. Lab Delo. 1984;(6):362-5. [Article in Russian]

21. Hisin PJ, Hilf R. A fluorometric method for determination of oxidized and reduced glutathione in tissues. Anal Biochem. 1976;74(1):214-26.

22. Misra HP, Fridovich I. The role of superoxide anion in the autoxidation of epinephrine and a simple assay for superoxide dismutase. J Biol Chem. 1972;247(10):3170-5.

23. Labygina AV, Kolesnikova LI, Grebenkina LA, Darenskaya MA, Kurashova NA, Dolgikh MI, et al. [Retinol content and reproductive disorders in residents of Eastern Siberia (literature review)]. Human Ecology. 2018;(4):51-58 [Article in Russian]. 24. Kolesnikova LI, Semenova NV, Labygina AV. [Evaluation of antioxidant status in women with endocrine infertility]. Zhurnal Akusherstva i Zhenskikh Boleznei. 2010;59(4):57-60. [Article in Russian].

25. Abramova SV, Kurganova OYu, Bogomolova TYu, Mironova IN. ESTIMATION OF INDICATORS OF ANTIOXIDANT STATUS IN PATIENTS WITH VIOLATION OF FERTILITY OF ENDOCRINE GENESIS. International Research Journal. 2017;12(66, Part 4):91-93.

26. Adeoye O, Olawumi J, Opeyemi A, Christiania O. Review on the role of glutathione on oxidative stress and infertility. JBRA Assist Reprod. 2018 Mar 1;22(1):61-66. doi:
10.5935/1518-0557.20180003.

27. Adeoye O, Olawumi J, Opeyemi A, Christiania O. Review on the role of glutathione on oxidative stress and infertility. JBRA Assist Reprod. 2018 Mar 1;22(1):61-66. doi: 10.5935/1518-0557.20180003.

28. Mulla A, Fazari A, Elkhouly M, Moghaddam N. Role of Antioxidants in Female Fertility. Open Journal of Obstetrics and Gynecology. 2018;(8):85-91. doi: 10.4236/ojog.2018.82011. 29. Ross SA, McCaffery PJ, Drager UC, De Luca LM. Retinoids in embryonal development. Physiol Rev. 2000 Jul;80(3):102154. doi: 10.1152/physrev.2000.80.3.1021.

30. Babaei H, Derakhshanfar A, Nematollahi-Mahani SN, Fathemeh N, Zeraatpisheh A. Morphologic changes in fresh and vitrified mouse ovaries after retinol palmitate administration. Iranian Journal of Reproductive Medicine. 2005;3(2):62-67.

31. Nikitenko LL, Kolesnikov SI. The role of adrenomedullin in the biology of the endothelial cell. M.: GEOTAR Media; 2007. [In Russian].

32. Aisaka K. [Effects of prolactin on lipid metabolism (author's transl)]. Nihon Sanka Fujinka Gakkai Zasshi. 1982 May;34(5):559-68. [Article in Japanese].

33. Nilsson L, Binart N, Bohlooly-Y M, Bramnert M, Egecioglu E, Kindblom J, Kelly PA, Kopchick JJ, Ormandy CJ, Ling C, Billig H. Prolactin and growth hormone regulate adiponectin secretion and receptor expression in adipose tissue. Biochem Biophys Res Commun. 2005 Jun 17;331(4):1120-6. doi: 10.1016/j.bbrc.2005.04.026.

34. Nilsson LA, Roepstorff C, Kiens B, Billig H, Ling C. Prolactin suppresses malonyl-CoA concentration in human adipose tissue. Horm Metab Res. 2009 Oct;41(10):747-51. doi: 10.1055/s-0029-1224181. Epub 2009 Jun 23. 